\title{
AS IDÉIAS DE PETER HÄBERLE E A ABERTURA DA INTERPRETAÇÃO CONSTITUCIONAL NO DIREITO BRASILEIRO*
}

\section{INOCÊNCIO MÁRTIRES COELHO**}

Dois fatos da maior importância para o aprimoramento do modelo brasileiro de controle jurisdicional de constitucionalidade das leis acabaram de acontecer no País. Referimo-nos à publicação da obra de Peter Häberle $A$ Sociedade Aberta dos Intérpretes da Constituição, traduzida e apresentada por Gilmar Ferreira Mendes, e à remessa ao Congresso Nacional do Projeto de Lei $n^{2} 2.960$, de 1997, de iniciativa do Poder Executivo, que dispõe sobre o processo e julgamento da ação direta de inconstitucionalidade e da ação declaratória de constitucionalidade perante o Supremo Tribunal Federal.

Intimamente relacionados, esses fatos espelham o nosso amadurecimento no trato dessa matéria, a qual envolve problemas da maior relevância para toda a comunidade. Embora, à primeira vista, possa parecer um assunto técnico, merecedor de atenção exclusivamente por parte de iniciados ou de especialistas, a leitura da sua exposição de motivos evidencia que essa proposta legislativa interessa a toda a sociedade e não apenas aos profissionais do direito, como se comprovará no curso desta exposição.

Constitucionalista dos mais renomados da atualidade, com suas obras sendo objeto de reflexão e debate nos mais importantes centros universitários do mundo, Peter Häberle destaca-se por uma visão republicana e democrática da interpretação da Constituição, centrada na idéia de que uma sociedade aberta exige uma interpretação igualmente aberta de sua lei fundamental, até porque "no processo de interpretação constitucional estão potencialmente vinculados todos os orgãos estatais, todas as potências públicas, todos os cidadãos e grupos, não sendo possível estabelecer-se um elenco cerrado ou fixado com numerus clausus de intérpretes da Constituição".

1 A Sociedade Aberta dos Intérpretes da Constituição: contribuição para a interpretação pluralista e "procedimental" da Constituição. Porto Alegre, Sérgio Antonio Fabris Editor, 1997, p. 13.

* Palestra proferida na Faculdade de Direito da Universidade de Coimbra em 12/1/98.

** Professor Titular da Faculdade de Direito da Universidade de Brasilia.

R. Dir. Adm.,

Rio de Janeiro, 211: 125-134, jan./mar. 1998 
Nessa ordem de idéias, ele observa que a teoria da interpretação constitucional, durante muito tempo, esteve vinculada a um modelo de interpretação de uma sociedade fechada, concentrando-se primariamente na interpretação constitucional dos juízes e nos procedimentos formalizados, do que resultou empobrecido o seu âmbito de investigação. Por isso, é chegada a hora de uma viragem hermenêutica radical para que a interpretação constitucional - que a todos interessa e a todos diz respeito - seja levada a cabo pela e para a sociedade aberta e não apenas pelos operadores oficiais.

Em suma, no contexto de um Estado de direito, que se pretende democrático e social, torna-se imperioso que a leitura da Constịtuição se faça em voz alta e à luz do dia, no âmbito de um processo verdadeiramente público e republicano, pelos diversos atores da cena institucional - agentes políticos ou não - porque, ao fim e ao cabo, todos os membros da sociedade política fundamentam na constituição, de forma direta e imediata, os seus direitos e deveres. ${ }^{2}$

Em tema de direitos fundamentais - e.g. liberdade de cátedra, de criação artística, de imprensa e de organização sindical - é de todo evidente que sem a participação dos seus destinatários, daqueles que vivenciam esses direitos, não se produz uma interpretação sequer razoável do texto constitucional.

O mesmo se diga com relação àqueles direitos cujo âmbito de proteção envolve conteúdos só revelados com a ajuda hermenêutica de intérpretes não-jurídicos, como é o caso dos direitos das populações indígenas, nos termos em que são reconhecidos pelo artigo 231 da Constituição do Brasil. Sem o apoio dos próprios índios, de antropólogos e de indigenistas - que, aliás, participaram do processo constituinte - o juiz não conseguirá sequer ler esse dispositivo constitucional.

Com base na experiência, obviamente em razão do fato de vivermos numa sociedade razoavelmente pluralista e democrática, pode-se dizer que, até certo ponto, essa abertura hermenêutica já existe entre nós e que ela se manifesta difusamente pelo modo como os agentes políticos aplicam a Constituição nas diversas instâncias de decisão - , do que resulta minimamente ampliado o círculo dos participantes da realização constitucional, assim como assegurada, embora também em grau mínimo, a influência social sobre os funcionários da interpretação constitucional.

Nesse contexto, o que se faz necessário, portanto, é institucionalizarmos procedimentos que densifiquem a intervenção de terceiros no processo de interpretação e aplicação da lei fundamental. Afinal de contas, independentemente das suas peculiaridades, nunca é demais relembrar que no âmbito da jurisdição constitucional, aqueles que não participarem da relação processual, que não assumirem qualquer posição no processo ou que, até mesmo, ignorarem a sua existência, poderão considerar-se politicamente não alcançados pelos efeitos da coisa julgada e, por via de consequiência, autorizados a ignorar a força normativa da Constituição.

Por isso, também sob esse ângulo, digamos procedimental, afigura-se conveniente que todos possam participar do jogo interpretativo, quando mais não seja para que não se animem a virar-lhe a mesa ou a contestar o seu resultado. $\mathrm{Na}$ medida em

2 Gomes Canotilho. Direito Constitucional. Coimbra, Almedina, 1991, p. 208. 
que são partículas da Constituição, como diria Lassalle, ou agentes conformadores da realidade constitucional e forças produtivas de interpretação, na linguagem de Häberle, esses segmentos sociais não podem ficar à margem do processo de revelação da vontade constitucional.

Nessa perspectiva, a ampliação do número dos tradutores constitucionais autorizados, ao mesmo tempo em que promove a integração das diferentes perspectivas hermenêuticas, opera como instrumento de prevenção e solução de conflitos. Noutras palavras, na medida em que asseguram o dissenso hermenêutico e racionalizam as divergências de interpretação em torno da Constituição, idéias como as de Häberle colaboram, decisivamente, para preservar a unidade política e manter a ordem jurídica, que são os objetivos fundamentais de toda constituição. ${ }^{3}$

Subjacente a essa compreensão ampliada e enriquecida da interpretação constitucional - a que serve de fundamento e legitimação - existe uma concepção hermenêutica da maior consistência, segundo a qual Constituição e realidade constitucional se implicam com tamanha intensidade, que a norma jurídica deixa de ser vista como o pressuposto para ser encarada como o resultado da interpretação, resultado a que se chega no curso de um processo no qual o programa normativo e o âmbito normativo, em permanente interação dialética, reciprocamente se exigem, se esclarecem, se iluminam e se revelam.

Daí, precisamente, a afirmação de Häberle, na linha de um pensamento de aceitação crescente, a nos dizer que não existe norma jurídica, senão norma jurídica interpretada. ${ }^{4}$

Do ponto de vista procedimental, para que essa abertura hermenêutica possa gerar frutos segundo a sua espécie, faz-se necessário integrar a realidade no processo de interpretação constitucional, o que só se alcançará se forem criados mecanismos idôneos para captar, filtrar e absorver os anseios de todos os atores da cena social.

É que, embora intérpretes não-oficiais da Lei Fundamental, nem por isso os chamados grupos intermediários e o próprio cidadão, deixam de ser legítimos interessados na sua aplicação. Detentores permanentes da privilegiada condição de sujeitos do processo constituinte e de realizadores e destinatários finais da Constituição, de nada lhes adiantaria ostentar esse título de nobreza se lhes fosse vedado participar do processo de tradução da vontade constitucional.

Destarte, se a jurisdição constitucional, de forma natural e continuada, conseguir preservar a sintonia entre o programa normativo e o âmbito normativo, vale dizer, entre a interpretação constitucional e a realidade constitucional - tarefa que será tanto mais facilitada, quanto maior for a sua capacidade para auscultar e compreender os anseios sociais -, as cortes que exercem essa jurisdição política estarão legiti-

3 Konrad Hesse. Concepto y Cualidad de la Constitución, in Escritos de Derecho Constitucional, Madrid, Centro de Estudios Constitucionales, 1983, pp. 8/9).

4 Entre nós, pioneiramente, Miguel Reale teve oportunidade de afirmar que "o direito é norma e situação normada e que "a norma é a sua interpretação". Filosofia do Direito. São Paulo, Saraiva, 1982, p. 594: Teoria Tridimensional do Direito - Situação Atual. São Paulo, Saraiva, 1986, p. 98; Fontes e Modelos do Direito - Para um novo paradigma hermenêutico. Sāo Paulo, Saraiva, 1994, p. 33. 
mando os resultados da sua atividade hermenêutica e, provavelmente, até mesmo preservando a sua própria existência no marco do Estado Democrático de Direito.

Afinal de contas, embora situadas fora e acima dos demais Poderes ${ }^{5}$ - enquanto instâncias supremas cuja atividade hermenêutica não sofre qualquer limitação juridica -, essas cortes extraordinárias são, também elas, simples criaturas constitucionais e, nessa condição, não se acham imunes às reações sociais, podendo vir a desaparecer na voragem de qualquer processo constituinte.

Por isso mesmo, sem que precisem andar a reboque das maiorias ocasionals, embora não possam nem devam ignorar a sua existência, se conseguirem preservar aquele equilíbrio instável entre norma e realidade constitucional — e na medida em que o consigam - os tribunais constitucionais continuarão a contar com o respaldo da opinião pública para reescrever de fato a Constituiçãó, sem que a ninguém, ocorra sequer indagar sobre a legitimidade desse procedimento.

Nessa visão, quanto mais aberto à participação social se mostrar o processo de interpretação e aplicação da Carta Política, mais consistentes e mais eficazes serão as decisões da jurisdição constitucional enquanto respostas hermenêuticas - temporalmente adequadas - às perguntas da Sociedade sobre o sentido, o alcance e a própria necessidade da sua Constituição.

À luz dessas premissas, ninguém teria objeções, pelo menos em tese, às propostas de Peter Häberle para a construção de uma sociedade aberta dos intérpretes da Constituição, até porque - embora omitida qualquer relação de parentesco elas se mostram essencialmente idênticas às incômodas e sempre atuais reflexōes de Fernando Lassalle sobre a presença dos fatores reais de poder na vida das constituições. ${ }^{7}$

Ocorre que uma simples leitura do extenso rol dos agentes que Peter Häberle reputa igualmente legitimados a interpretar a Constituição aponta, desde logo, para

5 Mauro Cappelletti. $O$ controle de constitucionalidade das leis nos sistema das funçōes estatais in Revista de Direito Processual Civil. São Paulo, Saraiva, 1961, vol. 3, p. 38.

6 A propósito do relevo institucional e do poder criador da jurisdição constitucional, afirmou Francisco Campos, em 2/4/41, na solenidade de abertura dos trabalhos do STF: "Juiz das atribuiçōes dos demais Poderes, sois o próprio juiz das vossas. O domínio da vossa competência é a Constituiçāo, isto é, o instrumento em que se define e se especifica o Governo. No poder de interpretá-la está o de traduzi-la nos vossos próprios conceitos. Se a interpretação, e particularmente a interpretafão de um texto que se distigue pela generalidade, a amplitude e a compreensão dos conceitos, nāo é operação puramente dedutiva mas atividade de natureza plástica, construtiva e criadora, no poder de interpretar há de incluir-se, necessariamente, por mais limitado que seja, o poder de formular. $O$ poder de especificar implica margem de opçāo tanto mais larga quanto mais lata, genérica, abstrata, amorfa ou indefinida a matéria de cuja condensação há de resultar a espécie". O Poder Judiciário na Constituição de 1937. in Direito Constitucional. Rio, Forense, 1942, p. 367.

7 Em estudo a ser publicado brevemente sob o título Konrad Hesse/Peter Háberle: um retorno aos fatores reais de poder, tentaremos demonstrar que, a despeito de sua inegável importância, não são originais as idéias desse jurista sobre a necessidade de se abrir a interpretação da Constituição aos agentes conformadores da realidade constitucional ou às forças produtivas de interpretaçảo. Na essência, como na forma, achamos que elas são descendentes hermenêuticas das reflexōes de Lassalle sobre a essência da Constituifäo. 
a necessidade de se racionalizar o processo de auscultação daquilo que têm a dizer esses novos protagonistas da interpretação constitucional. ${ }^{8}$

Caso contrário, isto é, se nos descuidarmos dessa exigência de racionalização, como o próprio Häberle reconhece $-\mathbf{e}$ a crítica tem apontado com freqüência a exegese constitucional poderá dissolver-se num grande número de interpretaçōes e de intérpretes, instaurando-se uma babel hermenêutica que, inevitavelmente, comprometerá a unidade e a força normativo-agregadora da Constituição.

Nessa linha de pensamento, não constituiria exagero dizermos que, levada a extremos, essa dissolução hermenêutica daria ensejo a conflitos entre a Carta Política e uma realidade inconstitucional, hipótese em que, via de regra, os fatores reais de poder acabam prevalecendo sobre o texto da Constituição folha de papel, que se torna perempta e, por isso, deve ser substituída por uma normatividade circunstancialmente adequada.

Conhecedor dessa realidade e sinceramente empenhado em modernizar a ordem jurídica do País - nesse propósito compreendida, obviamente, a abertura racional da nossa jurisdição constitucional - , o Ministro da Justiça constituiu uma grande comissão de juristas", aos quais atribuiu a incumbência de formular estudos para a reforma das leis que dispõem sobre ação popular, ação civil pública, mandado de segurança e representação interventiva, assim como para elaborar projetos de lei sobre o mandado de injunção, o habeas data, a ação direta de inconstitucionalidade e a ação declaratória de constitucionalidade.

Com resultado inicial dos trabalhos dessa comissão, foi apresentado anteprojeto de lei, cuja versão inicial esteve a cargo do renomado constitucionalista Gilmar Ferreira Mendes, para regular o processo e julgamento da ação direta de inconstitucionalidade e da ação declaratória de constitucionalidade perante o Supremo Tribunal Federal.

Embora inspirada por aquele propósito modernizador, em cujo âmbito, insistase, está inserida a necessidade de se promover, racionalmente, a abertura hermenêutica do modelo brasileiro de controle jurisdicional da constitucionalidade das leis, a

8 Além dos intérpretes oficiais e à margem dos procedimentos formalizados de interpretaçăo constitucional, Peter Häberle considera intérpretes igualmente legítimos da Constituição os agentes conformado. res da realidade constitucional, que representam forças produtivas de interpretação, a saber: o recorrente e o recorrido, no recurso constitucional (verfassungsbeschewerde), enquanto agentes que justificam a sua pretensão e obrigam o Tribunal Constitucional a tomar uma posição ou a assumir um diálogo jurídico (Rechtsgespräch); outros participantes do processo, que têm direito de se manifestar ou de integrar a lide; ou que são, eventualmente, convocados pela própria Corte; pareceristas ou experts; peritos e representantes de interesses; grupos de pressāo organizados, a opiniāo pública democrática e pluralista e o processo político; a imprensa; os partidos políticos fora do seu âmbito de atuação organizada; as igrejas e as organizaçōes religiosas; as associaçōes de país; as escolas da comunidade; os meios universitário, cientifico e artístico; a doutrina constitucional, por si e por sua atuação para tematizar a participação das outras forças produtoras de interpretação etc. Cf. Hermenêutica Constitucional, cit., pp. 2022.

9 Sob a presidência do professor Caio Tácito, integram essa Comissão os juristas Ada Pelegrini Grinover, Álvaro Villaça de Azevedo, Antonio Herman Vasconcelos Benjamin, Carlos Alberto Direito, Gilmar Ferreira Mendes, Jamyr Dall'Agnol, Luiz Roberto Barroso, Manoel André da Rocha, Roberto Rosas e Ruy Rosado de Aguiar Junior. 
proposta legislativa, nos termos em que foi enviada ao Congresso Nacional Projeto de Lei $n^{2}$ 2.960, de 1997, do Poder Executivo - acabou ficando aquém das expectativas, precisamente no que se refere ao tamanho da pretendida abertura.

É que, atentos ao peso da tradição $o^{10}$ e certamente contingenciados pela necessidade de obter o nihil obstat do STF, os redatores finais do projeto, mesmo tendo facilitado a consulta aos diferentes segmentos sociais interessados nas respostas da jurisdição constitucional, se viram obrigados a limitar essa tomada de opiniōes e, por via de conseqüência, também as perguntas destinadas a esclarecer $o$ sentido da Constituição.

Com efeito, em clara oposição às idéias de publicação do processo de controle da constitucionalidade das leis - Peter Häberle, como vimos, preconiza uma visão republicana e democrática de interpretação constitucional -, o projeto preferiu prestigiar jurisprudência regressiva incorporada a norma simplesmente regimental do STF para, sem razão aparente, vedar a intervenção de terceiros na ação direta de inconstitucionalidade, assim como na ação declaratória de constitucionalidade, muito embora tal restrição não decorra da lei ou, mesmo indiretamente, do texto da Constituição.

Ao contrário, à luz da história da ação direta no direito brasileiro, parece que o certo seria liberalizar-se a sua propositura, pelo menos a partir da Carta de 1988, que rompeu com a tradição de se concentrar numa só pessoa - o Procurador-Geral da República - a prerrogativa de promover essa demanda constitucional perante o STF.

Pois bem, a despeito dessa opção conservadora e não republicana da interpretação constitucional, a proposta contém várias aberturas hermenêuticas - umas bem significativas, outras nem tanto - destinadas, todas, a conferir um caráter pluralista à processo objetivo de controle abstrato de constitucionalidade.

Entre as aberturas, digamos, menores, o projeto permite que os autores constitucionalmente legitimados a instaurar esse tipo de processo (CF - artigo 103, caput, e $\S 4^{\circ}$ ) possam manifestar-se, por escrito, sobre o objeto da ação, pedir a juntada de documentos que se considerem úteis para o exame da matéria, assim como apresentar memoriais.

Tendo em conta que esses autores, a rigor, não podem ser considerados terceiros interessados - até porque, por direito próprio, têm legitimidade para propor diretamente a mesma ação ao invés de intervirem em demanda constitucional alheia é que nós consideramos sem maior expressão essa porta de acesso à relação processual constitucional. Pelo menos enquanto instrumento democratizador da leitura da Constituição.

Contra este nosso entendimento, sustenta Gilmar Ferreira Mendes - com quem discutimos este e outros pontos do Projeto de Lei $n^{2}$ 2.960/97 - que essa abertura

10 A respeito da tradiçāo, como categoria hermenêutica, cumpre ter presente a advertência de Gadamer no sentido de que, embora deva olhar para o passado, o intérprete não pode ignorar-se a si mesmo, nem desprezar a concreta situaçāo histórica em que se encontra. Cf. Verdad y Método. Salamanca, Sigueme, 1993, vol. I, pp. 396/401. 
é muito mais significativa do que imaginamos e que a sua real dimensão somente será avaliada corretamente se tivermos presente o fato de que, sem a permissão criada pela citada proposta legislativa, os demais agentes indicados no art. 103 da Constituição não teriam direito próprio para intentar aquelas demandas constitucionais.

É que - prossegue o consagrado constitucionalista -, sendo-lhes originariamente alheias, essas ações não poderiam ser propostas por autores outros, os quais, precisamente em razão dessa estranheza, não preencheriam o requisito da relação de pertinência que a Excelsa Corte, a despeito do caráter impessoal e objetivo desse tipo de demanda, tem exigido para conhecer da ação direta de inconstitucionalidade."

Mesmo assim, nada nos garante que o STF, apesar ou por causa dessa abertura, não venha formular essa mesma exigência para que, nas ações diretas intentadas por terceiros, aqueles outros autores possam manifestar-se, por escrito, sobre o objeto da ação e pedir a juntada de documentos reputados úteis para o exame da matéria, bem como apresentar memoriais. Afinal de contas, dado o caráter relativamente aberto e indeterminado do conceito de relação de pertinência, parece não haver limites ao juízo de admissibilidade das cortes constitucionais.

Nossa experiência, no particular, não enseja muito otimismo, até porque continua válida a lição de Rui Barbosa, ministrada nos primórdios da República, de que o Supremo Tribunal Federal - como, de resto, todas as cortes constitucionais ${ }^{12}-$ é o único juiz da sua própria autoridade.

Bem mais significativa do que a mencionada fenda hermenêutica, embora vocacionada para produzir resultados apenas por via indireta, afigura-se a faculdade conferida ao relator para, em caso de necessidade de esclarecimento de matéria ou circunstância de fato, ou de notória insuficiência das informações existentes nos autos, requisitar informações adicionais, designar peritos para emitir parecer sobre a questão, ou fixar data para, em audiência pública, ouvir depoimentos de pessoas com experiência e autoridade na matéria.

Nessa mesma linha, embora com um grau de importância bem mais elevado, é de se considerar a permissão, igualmente concedida ao relator, para solicitar informações aos Tribunais Superiores, aos Tribunais federais e aos Tribunais estaduais acerca da aplicação da norma impugnada.

Imaginando-se a riqueza das informações que essas instâncias de decisão poderão transmitir ao Supremo Tribunal Federal sobre a aplicação da norma questionada - não nos esqueçamos de que interpretar é sempre também aplicar ${ }^{13}$-, devemos esperar que a nossa Corte Suprema, explorando todas as virtualidades dessas aber-

II A propósito dessa exigência criada pelo STF, vale registrar a opinião do próprio Gilmar Ferreira Mendes: "Cuida-se de inequivoca restrição ao direito de propositura, que, em se tratando de processo de natureza objetiva, dificilmente poderia ser formulada até pelo legislador ordinário. A relaçāo de pertinência assemelha-se muito ao estabelecimento de uma condiçāo da ação - análoga, talvez, ao interesse de agir - que não decorre dos expressos termos da Constituição e parece ser estranha à natureza to processo de controle de normas". Jurisdição Constitucional - O controle abstrato de normas no Brasil e na Alemanha. São Paulo, Saraiva, 1996, p. 142.

12 Vide Notas 5 e 6.

13 Hans-Georg Gadamer, op. e vol. cits., p. 380. 
turas procedimentais, venha a ampliar consideravelmente o seu horizonte de compreensão e, por via de conseqüência, a decidir melhor as demandas constitucionais.

Noutras palavras, se tirar todo o proveito do quanto the poderão proporcionar esses privilegiados sensores sociais, o STF enriquecerá a interpretação constitucional pela reintegração entre domínio normativo e programa normativo, entre realidade constitucional e texto constitucional, reintegração que se faz tanto mais necessária quanto sabemos que esses elementos se implicam e se exigem reciprocramente, como condição de possibilidade da compreensão, da interpretação e da aplicação de qualquer modelo jurídico.

De resto - como lembraram, com toda a pertinência, os próprios autores dessa proposta legislativa - a controvérsia constitucional não configura uma simples questão juridica de aferição da legitimidade da lei em face da Constituição. Muito mais complexa do que uma asséptica comporação lei com lei, a questão constitucional, até mesmo pelas conseqüências do seu desfecho, exige um acurado cotejo entre a norma e a situação normada, porque sem o exame dos fatos nada nos dizem as formalizações jurídicas. ${ }^{14}$

Noutros termos, porque o programa normativo e o domínio normativo se implicam e se exigem reciprocramente, com intensidade tamanha que um só é o que é enquanto o é para o outro - tal como se vinculam sujeito e objeto na relação do conhecimento - a correlação fato-norma é da própria essência do direito, que só é o que é enquanto se manifesta como ordenação jurídica da vida social.

Igualmente significativa se mostra a possibilidade de que — atento à relevância da matéria e à representatividade dos postulantes - , o relator possa autorizar que qualquer outro órgão ou entidade se manifeste no processo na condição de amicus curiae $^{15} \mathrm{e}$, por essa forma, venha a contribuir para que o Tribunal decida as questões constitucionais com pleno conhecimento de todas as suas implicaçöes ou repercussões.

Muito embora o projeto faça do relator o juiz exclusivo da conveniência e da oportunidade dessas manifestações, só o fato de ensejá-las já representa significativo avanço, sobretudo num contexto de restrições crescentes e sistemáticas, em que sempre se proclamou o caráter reconhecidamente objetivo do processo de controle de constitucionalidade em abstrato para estreitar os limites das controvérsias cons-

14 A propósito, observa Karl Larenz, na linha do pensamento de Martin Kriele, que não se pode interpretar nenhum texto jurídico senão confrontando-o com problemas jurídicos concretos, reais ou imaginários, isto é, com soluções que se procuram para os casos ocorrentes, porque somente na sua aplicação aos casos e na concretização, que assim necessariamente se processa, é que se revela, completamente, o conteúdo significativo de uma norma e esta cumpre a sua funçāo de regular situaçōes concretas. Metodologia da Ciência do Direito. Lisboa, Gulbenkian, $I^{2}$ ed., 1978, p. 396.

is Conforme o Law Dictionary, de Steven H. Gifis, Barron's Educational Series, Inc. Woodbury, Nova York, 1975, pp. 11 1/12, Amicus Curiae é o amigo da corte, aquele que lhe presta informaçōes sobre matéria de direito, objeto da controvérsia. Sua função é chamar a atenção da corte para alguma matéria que poderia, de outro forma, escapar-lhe à atençāo. Um memorial de amicus curiae é a peça produzida por quem nāo é parte numa açāo, com vistas a auxiliar a corte, com informaçōes necessárias, para que ela possa tomar uma decisão correta ou com vistas a advogar um determinado resultado em nome de interesses públicos ou privados de terceiros, que serão indiretamente afetados pela solução da disputa. 
titucionais e, por essa forma, descartar tudo quanto, subjetivamente, pudesse dificultar a leitura oficial da Constituição.

A propósito, registre-se que mesmo depois de ampliado o número dos autores legitimados a instaurar o contencioso de constitucionalidade na via da ação direta - ou até mesmo por causa dessa ampliação —, embora sem apoio visível na Constituição, ou sequer em norma legal, o Supremo Tribunal Federal continuou restringindo o acesso da cidadania a esse modo expedido de provocar a jurisdição constitucional. ${ }^{16}$

Admitida, pela forma indicada, a presença do amicus curiae no processo de controle de constitucionalidade, não apenas se reitera a impessoalidade da questão constitucional, como também se evidencia que o deslinde desse tipo de controvérsia interessa objetivamente a todos os indivíduos e grupos sociais, até porque ao esclarecer o sentido da Carta Política, as cortes constitucionais, de certa maneira, acabam reescrevendo as constituiçōes.

Nessa perspectiva, se é verdade que os autores ingleses consideram os statutes do seu Parlamento como erratas e adendas do common law, não seria exagerado dizermos que, à luz da experiência da jurisdição constitucional, os julgados das cortes que a exercem têm funcionado como correções e acréscimos ao texto das constituiçōes.

Finalmente, o avanço mais significativo, consubstanciado no artigo 27 do projeto: - Ao declarar a inconstitucionalidade de lei ou ato normativo, tendo em vista razões de segurança jurídica ou de excepcional interesse social, poderá o Supremo Tribunal Federal, por maioria de dois terços de seus membros, restringir os efeitos dessa declaração ou decidir que ela só tenha eficácia a partir de seu trânsito em julgado ou de outro momento que venha a ser fixado.

Com essa fórmula, inspirada imediatamente na Constituição Portuguesa de 1976, mas historicamente amadurecida na experiência da nossa jurisdição constituição, tem-se em mira atenuar as conseqüências das declarações de inconstitucionalidade, em ordem a impedir que, por amor aos princípios, os juízes acabem contrariando a natureza das coisas, desnecessariamente aliás, porque a Constituição nem proíbe nem exige efeito retrotativo, como bem salientaram os autores do projeto.

Conscientes da gravidade e do risco de se atribuir semelhante prerrogativa a um tribunal - mesmo que essa corte seja o Supremo Tribunal Federal -, gravidade e risco que se potencializam pelo caráter aberto e indeterminado dos conceitos de segurança juridica e de excepcional interesse social, cuidaram os idealizadores da proposta de justificá-la à exaustão, certamente atentos à advertência de que o abandono dos precedentes exige não apenas a explicação ordinária das razões de fato e de direito que fundamentaram essa mudança de posição, como também uma justifi-

16 Sobre a jurisprudência de não-conhecimento das ações diretas de inconstitucionalidade de iniciativa das confederaçōes sindicais e entidades de classe de âmbito nacional (CF - art. 103, IX), na mesma linha do comentário registrado anteriormente (Nota 11), merece registro a avaliaçāo crítica de Gilmar Ferreira Mendes. Jurisdição Constitucional - O controle abstrato de normas no Brasil e na Alemanha, cit., pp. 138/145. 
cação adicional dos motivos que levaram o intérprete a se afastar do critério anterior. ${ }^{17}$

Afinal de contas, sempre se estendeu que uma lei declarada inconstitucional não é lei de forma alguma e, por isso, há de ser tida como nula e de nenhum efeito... Então, por que mudar? Por que abandonar esse velho e confortável entendimento, que tem a seu favor argumentos lógicos da maior consistência? Por que, enfim, preservar situações que se criaram ao abrigo de normas sabidamente inconstitucionais?

Simplesmente porque assim o exige a natureza das coisas e porque a vida do direito não tem sido lógica, tem sido experiência...

Pela radical mudança de perspectiva consubstanciada nessa ousada proposta, é de se considerar que aí se encontra a maior e a mais importante abertura em nosso processo de controle abstrato de constitucionalidade, porque dará ensejo a que o Supremo Tribunal Federal - alertado sobre todas consequiências das suas decisões —, venha a adotar, sem contorcionismos, uma realística jurisprudência de resultados, assumidamente inspirada nos valores da segurança juridica e do interesse social, que são congênitos à idéia de direito.

Em conclusão, muito embora não tenha ido tão longe quanto desejávamos, o Projeto de Lei $\mathrm{n}^{2} 2.960 / 97$ já representa um significativo avanço para a publicizaçāo e a democratização do modelo brasileiro de controle jurisdicional de constitucionalidade das leis.

Convertido em lei, depois de aperfeiçoado pelo Congresso Nacional, não temos dúvida de que abrirá caminho para a construção da nossa sociedade aberta de intérpretes da Constituição.

17 Robert Alexy. Teoria de la Argumentación Jurídica. Madrid. Centro de Estudios Constitucionales, 1989, p. 265; Aulis Aarnio. Lo Racional como Razonable, Madrid. Centro de Estudios Constitucionales, 1991, p. 260; Marina Gascón Abellán. La técnica del precedente y la argumentación racional. Madrid, Tecnos, 1993, pp. 39/40. 